\title{
AERODYNAMICS, STRUCTURAL CONFIGURATION AND MATERIALS OF HYPERSONIC AIRCRAFTS
}

\author{
Shivansh Upadhyay \\ Dept of Aeronautical Engineering \\ FGIET, Raebareli U.P. INDIA
}

\author{
Pramod Kumar \\ Dept. of Metallurgical Engineering \\ IIT BHU Varanasi U.P. INDIA
}

\author{
Ajay Kumar Maurya \\ Dept. of Mechanical Engineering, \\ NIT, Patna Bihar, U.P. INDIA
}

Abstract - Global networking is the demand of the whole world and time plays a very crucial role in it, and it also plays a very important role in fastest and the reliable means of transport that become necessary, the Bullet train and the Hyper loop Projects are the live examples in that context, various countries from across the globe accept these project and as we all know that aviation sector id the one of the fastest growing means of transport across the world. Challenges faces by the machineries on the ground operation can be handled easily as compared to the air that's why after various research in the era of subsonic has been carried out by many developed countries firstly in the field of military in the form of the weapons and the when that technology proven safe and reliable it has become granted for commercial uses in that context era of supersonic flight the first one has been started on date 26September 1976 by Concord but as per the safety concerns the era of supersonic has closed in 24 October 2003.

Till now hypersonic platforms comes under in the form of fighter aircraft and reconnaissance aircraft and missile based platforms the demand of all these is to ensure the fastest approach towards the mission with least tile and more precision for the various control systems has been developed and still upgrading Hypersonic jets like very remarkable SR71 of USAF is mile stone in that ere problems occurring in the field of structural material, aerodynamic model and the robust control systems to operate in such a critical speed. It contains a huge present and future aspect of learning and developing new technologies. The demand of the space exploration with hypersonic technology is nearly impossible to predict without Hypersonic speed.
Keywords - Networking, Hyper loop, SR71, Hypersonic, Supersonic.

\section{INTRODUCTION}

From early development of flights in the beginning of 1903the first successful notable flight the world observe the safety parameters of the flights and with the passage of time fast means of transportation is need to fulfilled by the aviation industry, earlier piston engine aircrafts are sub sonic and due to availability of material at that time it cannot carry enough flights for the longer duration. By the introduction of Aluminum and its alloys boost the Hypersonic era of aviation has begun with the development of the Missiles and Rockets but due to its futuristic importance and scope in military and further civil aviation sector it become the milestone in futuristic travels .Aviation designs and also the propulsion system through this Jet Aircrafts are introduced and when this jet propulsion technology introduced in military aviation require more fast aircrafts like supersonic jets speed more than Mach 1, and now in the 21century the requirement of futuristic aircraft based on all new propulsion system named Scram Jet who can fly Mach 10 at Hypersonic speed, as we saw with the variation of the flow of fluid over the surface of aircraft require lots of positive changes in propulsion system and in Aerodynamics and it starts from material and its behavior to sustain at that condition of five to six times to that of the sound it comes in Surface Problems, next one is Aerodynamics Stability and Control over the aircraft it is based on the various parameters and other one is Propellant used because weight is key factor in aviation and it is variable parameter. Hypersonic Aircrafts are the proceeds of the Supersonic aircrafts so their base is based on its operation, external environment play very important during in flight but it is not in space-based flights so 


\section{International Journal of Engineering Applied Sciences and Technology, 2019 \\ Vol. 4, Issue 7, ISSN No. 2455-2143, Pages 158-164 \\ Published Online November 2019 in IJEAST (http://www.ijeast.com)}

it's crucial to focus on both the factors in development and research.

\section{STRUCTURAL CONFIGURATION OF THE HYPERSONIC VEHICLES}

Structural configuration is the backbone of any idea; in case of the hypersonic vehicles it crucial to analyze all the desired perimeters carefully and implement it according to it's the demand. The era of development of the high-speed vehicles begin with the missiles, including the Intercontinental ballistic missiles following the development of various rockets like Mercury, Gemini, Apollo manned space flight missions all the mentioned vehicles are high speed crafts and its design and configuration withstand such high stress of the super or hypersonic flights. The shape is specified by three independent parameters according to NASA who is the leading developer and researches in this era are.

\subsection{BLENDED WING BOD CONFIGURATION}

The configuration is of delta plane form with elliptical cone forebody and elliptical cone afterbody. A given configuration was specified by the values of three independent body shape parameters: the sweepback of the body leading edge; The position of the breakpoint between the forebody and afterbody; and the ratio of the maximum cross section to body platform area. Results are presented in term of the maximum lift-to-drag ratio for complete configurations including fins. Today's delta wing body shape wing configuration are the initial stage of it and it is successfully proved in various supersonic aircrafts like French Dassult Mirage 2000 and Rafale and Indian light combat aircraft Tejas.

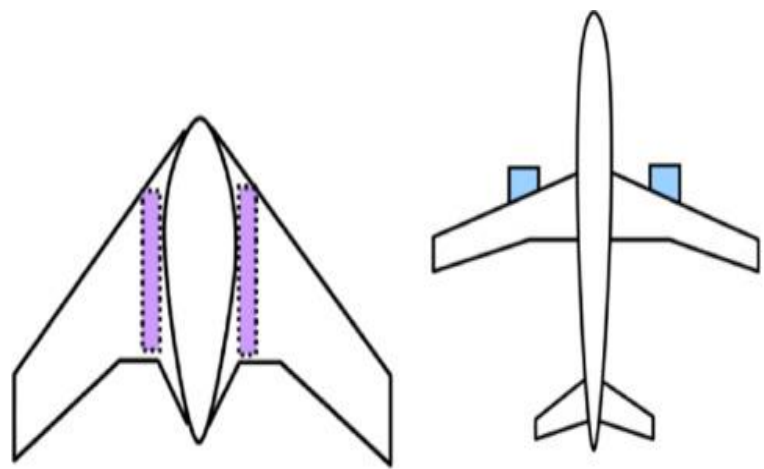

(a) Discrete BWB

(b) High By - pass Ratio Conventional Air craft

\subsection{Non-Vertical Tail Configuration}

It simply means the non-tail configuration is feasible with the blended wing configuration in which the wing blend with the fuselage along with tail section. Non tail configuration is in first view analysis is unstable because the tail provides the stability contribution to the aircraft. This type aircraft termed as the flying wing aircrafts. on-vertical tail model is proved in various aircrafts like B2 Spirit Stealth Bomber of the USAF in which both rolling and yawing is performed by the deflection of the ailerons. The stability of the aircraft is maintained by the computers.

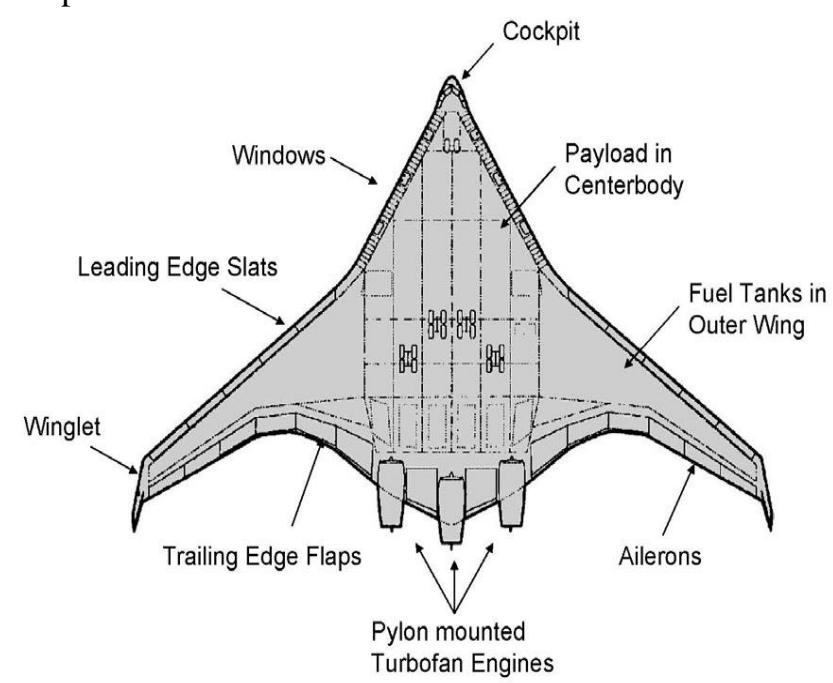

\section{MATERIALS FAVORABLE FOR HYPERSONIC FLIGHTS}

Selection of the material is one of the basic requirements and we know that the challenges of hypersonic regime flight is huge, material must have to be withstand at critical conditions. High speed flights primary problem is surface heating phenomenon which tends the material towards the failure cause damage to the body creates disintegration.

Aircrafts are normally using composite materials; the basic demand of the material is to be stronger and stiffer for its weight and must be cheap and lightweight. Meats are good in these characters but when any metal heated it loses its strength. Basically, use of the composite materials in hypersonic aircrafts/vehicles is fabricated inlayers they sometimes metal and their alloys and sometimes nonmetallic like various heat restraint Ceramics. The outer layer that is the skin which also has a huge responsibility to provide the thermal protection System from the aerodynamic heating. 


\section{International Journal of Engineering Applied Sciences and Technology, 2019 \\ Vol. 4, Issue 7, ISSN No. 2455-2143, Pages 158-164 \\ Published Online November 2019 in IJEAST (http://www.ijeast.com)}

Leading or Nose section interact with the shock cause large heat interaction during reentry and in atmosphere for that use of ceramic material is beneficiary whose tendency is to resist the heat and avoid the cracking and further disintegration of the structure.

\subsection{Thermal Protection System}

A thermal protection system or TPS is the barrier that protects a spacecraft during the searing heat of atmospheric during flight. The thermal conductivity of a particular TPS material is usually proportional to the material's density.

These materials are as follows.

- Ablative HEAT SHIELD

- Carbon phenolic is a very effective ablative material

- SLA-561V

- Phenolic -impregnated carbon ablator

- $\quad$ SIRCA Silicone-impregnated reusable ceramic ablator (SIRCA)

\subsection{Cooling techniques}

The cooling techniques to remove thermal energy from the surface of aircraft. It is broadly classified into two categories Active cooling and Passive cooling techniques. 'Radioactive shielding' (e.g. Molybdenum and Zirconium) and 'Insulation' (e.g. Dynaquartz) cooling are the most widely used techniques in the area of passive cooling.

\section{PERFORMANCE ANALYSIS OF THE HYPERSONIC VEHICLE}

Shock waves originating at the leading edge of the body lie close to the body so that the interaction with the body is strong. High temperatures exist in the regions between the shock waves and the body and it may be necessary to consider real gas effects (molecular vibration, dissociation, and ionization) when analyzing the flow fields. At very high $\mathrm{M}$, the shock waves may be assumed to be almost identical to the body, at least at the front portion of the body, and the molecules crossing the shock waves conserve the tangential component of the velocity but lose most of the normal component.

A plot of shock angle $B$ vs. L/D ranging from 16degrees to 24degrees and the trend to see. Here is that as the shock angle increases, the lift over drag ratio decreases and therefore it allows one to understand that the vehicle's height would be slender.

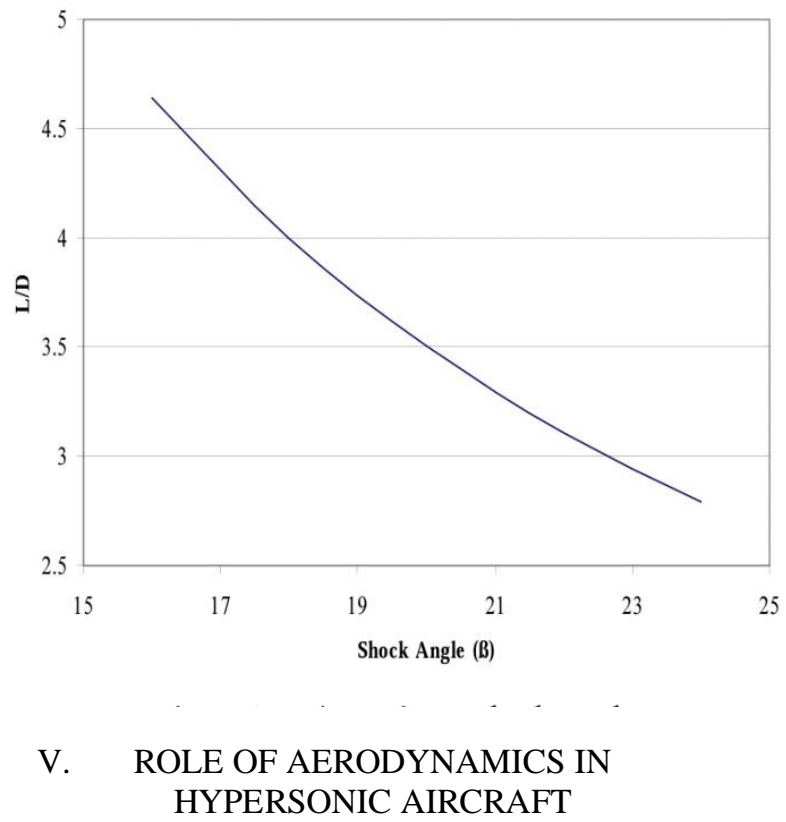

The term aerodynamics refers to the dynamics or the flow of gases around the surface of the vehicle and all its environmental interactions. The stability of the hypersonic aircraft is based on the flow of air around its outer surface so the proper flow if air around the surface is so important.

\subsection{Aerodynamic Heating}

It is one of the drastic phenomena happening during high speed flights, this cause the material failure and make their disintegration of the material during flight so this effect must be overcome by the various changes in the ion the shape if their vehicle and the material during design and in the manufacturing respectively.

This is illustrated by the looking at the relationship between the stagnation temperature and the static temperature.

$$
\left[T_{0} / T_{1}=\{1+(\gamma+1) / 2\} \times M^{2}\right]
$$

Due to this concern we need to cool the surface. Hypersonic vehicles flying at high altitudes where Reynolds Number is so low so that the flow becomes laminar and as we know that the heat transfer is much lower when the flow is laminar. Along with high temperature the is also the Compressibility effect and local air density varies due to Shocks and Expansion waves. 


\section{International Journal of Engineering Applied Sciences and Technology, 2019 Vol. 4, Issue 7, ISSN No. 2455-2143, Pages 158-164 \\ Published Online November 2019 in IJEAST (http://www.ijeast.com)}

The configuration of the nose is also a key factor which affect the surface heating phenomena, early us of sharp nose introduce which cause less drag favorable for high speed military aircraft but the disadvantage of this shape is that the shock formed at that surface above sonic is Attached Shock who vigorously increased the surface heating phenomenon instead of that further research proved that the Blunt Shape nose is beneficial for hypersonic aircrafts and missiles because shocks formed at that shape is Detached Shock which is above the surface the body avoid the heating.

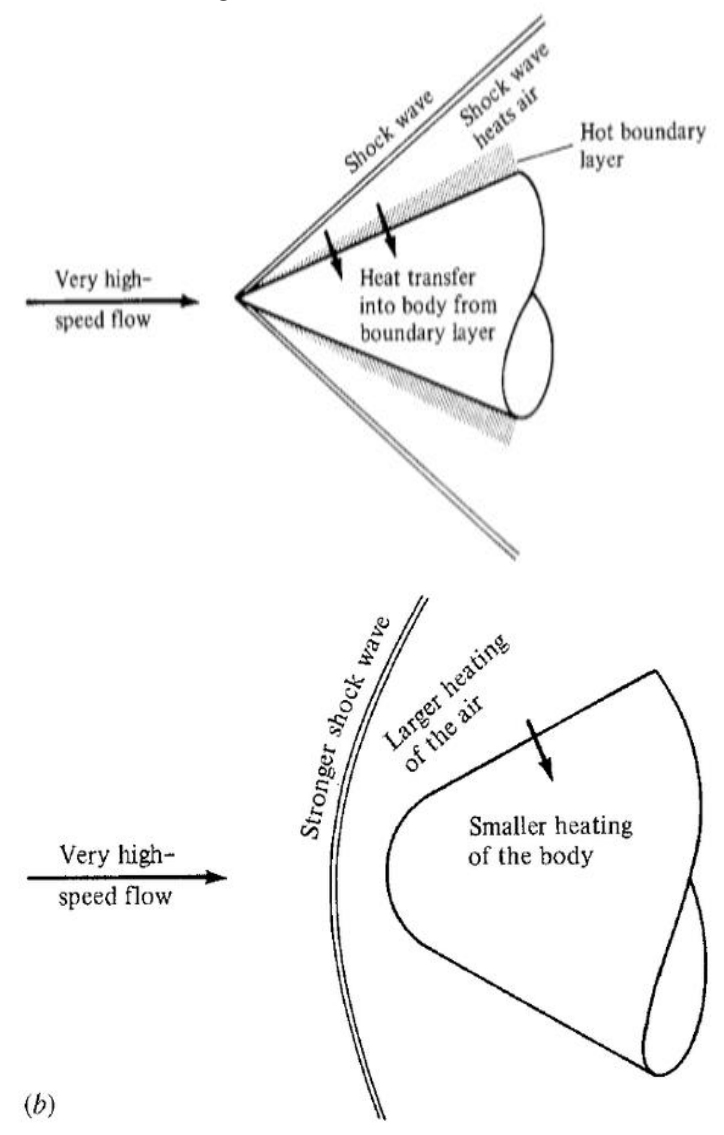

\subsection{Proposed Aerodynamics model of hypersonic vehicles}

Aerodynamics is the way of object to move through the air. Anything surrounded by the air even on the ground moving vehicles are affected by the aerodynamics. Hypersonic flight vehicles have a wide variety of application. Rockets and Missiles have become successors in that context. The challenge is to survive in the extensive and intensive aerodynamic heating environment for entry above which use of blunt shape gave successes like used in various reentry vehicles and in space craft's. Forces of flight are mainly Lift, Weight, Thrust and Drag it collectively decide the movement of the aircraft under proper aerodynamics. Forces of flight are mainly Lift, Weight, Thrust and Drag it collectively decide the movement of the aircraft under proper aerodynamics. The beginning of the era of fastest aircraft was in military aviation and the first research is carried out to build a fastest aircraft and it begins with the introduction of the Supersonic missiles and further aircrafts and so on. For any aircraft its aerodynamic model is very first parameter who will decide that is that aircraft withstand at that speed and this factor is directly affect the stability of the vehicle

- The configurations are of delta plan form with an elliptical cone fore body and an elliptical cross-section afterbody.

- A given configuration was specified by the values of three independent body shape parameters: the sweepback of the body leading edge;

- The position of the breakpoint between the forebody and afterbody; and the ratio of the maximum cross section to body platform area. Results are presented in term of the maximum lift-to-drag ratio for complete configurations including fins.

\section{HYPERSONIC FLIGHT STABLITY AND CONTROL}

The control system based on moving the center of gravity (i.e. moving internal weights) uses lift and drag forces to produce the required control moments. However, it may be difficult to achieve rapid changes in the moments that are needed to give fast enough control response. The use of this mechanism to achieve stable and steady sustained flight at hypersonic speeds.

\section{Surface controls}

- Surface control must be robust and reliable and also very effective during operation it is controlled by the various powerful computers and they also reduce the pilots work load so that pilot can focus on their Mission.

- AILERONS Plays the of main surface control for the Rolling and coupled roll yaw motions. Rolling and banking and it is mounted on the wings. Absence of the RUDDER because the presence of any vertical component against the hypersonic speed is difficult to withstands due to heavy aerodynamic drag. 
- YAWING controlling by the use of AILERONS and THRUST VECTORING NOZZLE.

- Yaw can be done by the changing the thrust of the engines and yawing is also coupled with the rolling so that the. This can already prove in various stealth aircraft like the B2 which is tailless.

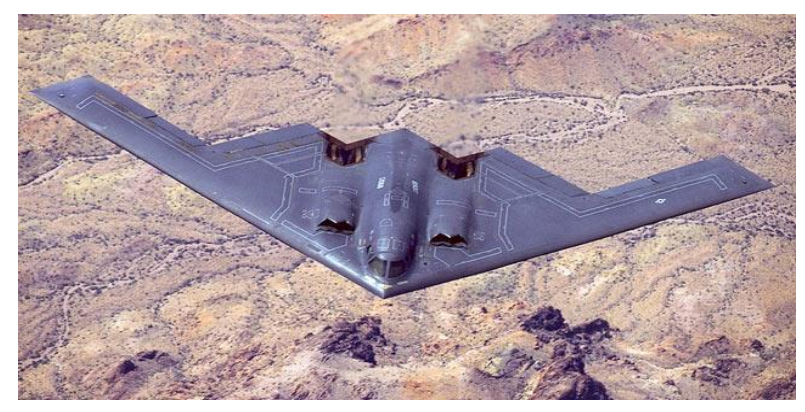

VII. PROPULTION SYSTEMS OF HYPERSONIC AIRCRAFTS

Propulsion system is the heart of any machine that produces power for its operation. In case of hypersonic aircrafts, it is quite complex because they need enormous amount of thrust and that thrust cannot be achieved by the conventional jet engines. Hypersonic vehicles are mainly use Ramjet or Scramjet propulsion system and one of the unconventional is the Hybrid RAMSCRAM and Pulsejet technology all of them are totally based on the continuity of flow who further takes the air breathing jet engines to its leading edge that is hypersonic flight. Propulsion system of hypersonic vehicles is classified in mainly four part like in other general propulsion systems.

INLET It is one of the very crucial parts before compression \& combustion processes. As we saw that in our convention turbofan and turbojet engines use of inlet work as diffuser section who realigns' the incoming flow and reduce its speed by increasing its pressure its positive impact applied on the size and numbers of the compressors blades which were using mainly for the compression process. In case of hypersonic aircrafts use of any moving parts are not feasible because the speed of flow is too high and moving parts too much drag due to friction and pressure difference.

DUCT (Diffuser \& Combustion Section) It is another important section include compression section and the combustion section. As we all know that the hypersonic propulsion system is favorable in flow processes. as flow enters into the diffuser section it reduces the flow speed by rising its pressure it is formed by changing the cross section of the duct, reduction of velocity of flow is necessary for the combustion part where fuel mix with air and ignition takes place. after combustion temperature of burnt gases get high and then expansion takes place.

NOZZLE it is last but most important part of engine because it produces thrust by exiting the mass flow of gasses cause due to the pressure difference. These are of various types varied according to need or requirement. In that case thrust vectoring nozzles are very beneficial during vectoring of thrust by area of cross section and one of the most important that it also controls the Backpressure.

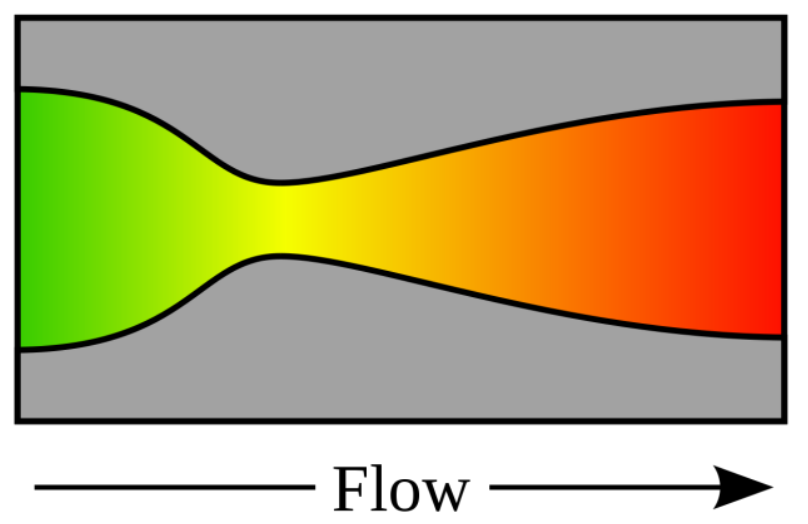

\subsection{RAMJET Propulsion System}

Ramjet propulsion system is remarkable form of turbofan engines it is also the air breathing engine but it does not have any moving part and that make it different from turbofan engines. It is mainly governed by the flow of air because for the initiation of RAMJET propulsion system supersonic flow of air is need to be required at the inlet it is the one of the major setback of this propulsion system which means it is not possible to takeoff the flight using that propulsion system we need some auxiliary propulsion system who took the aircraft in the air and propelled the aircraft to the supersonic speed and then at that time the working of Ramjet propulsion system begun.

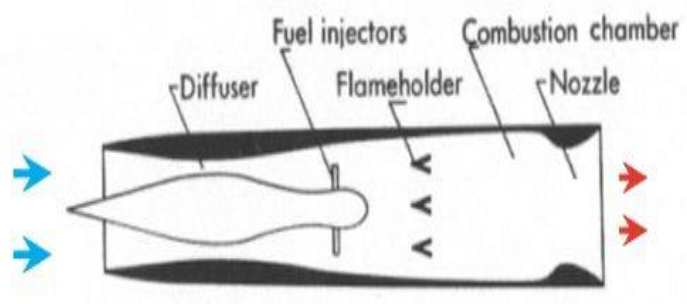




\section{International Journal of Engineering Applied Sciences and Technology, 2019 \\ Vol. 4, Issue 7, ISSN No. 2455-2143, Pages 158-164 \\ Published Online November 2019 in IJEAST (http://www.ijeast.com)}

\subsection{SCRAMJET Propulsion System}

Scramjet is procedure of the Ramjet all the processes in Scramjet is same as that of Ramjet in that the combustion takes place at the subsonic speed but in case of Scramjet combustion take place at supersonic flow that's why it is also called supersonic Ramjet this propulsion systems very favorable for the hypersonic regime of flight.

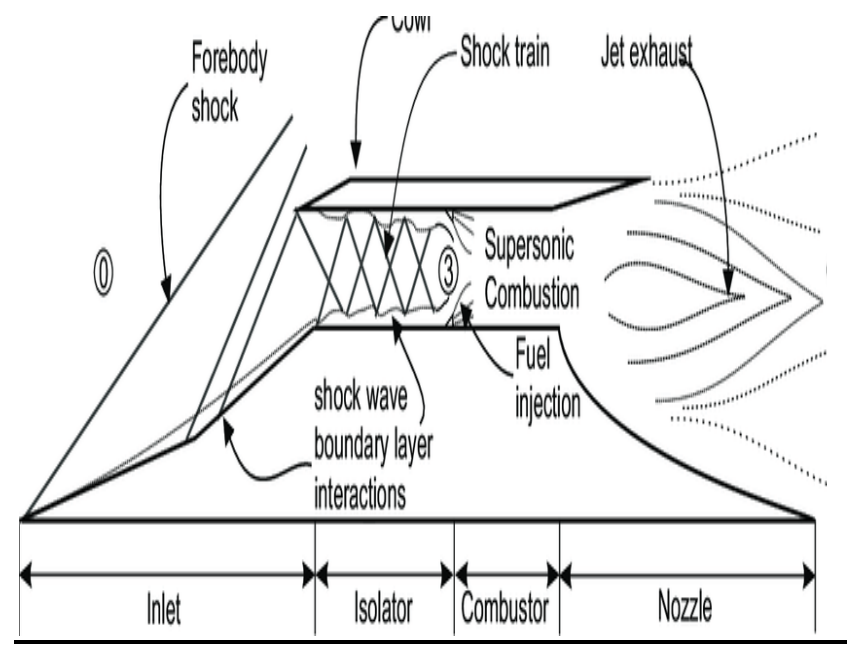

7.3 Hybrid RAMSCRAM propulsion system

It is based on the concept to combine the Ramjet and Scramjet propulsion system to get as much thrust to achieve hypersonic velocity. In this context scramjet engine is to be placed behind the Ramjet exhaust which is Supersonic. Scramjet demands supersonic flow and that flow should be maintained throughout the engine.

\section{FUTURE PERSPECTIVE AND CURRENT STATUS OF RESEARCH}

Many countries mainly successfully developed and tested their hypersonic aircrafts and weapons these are USA Russia China. These aircrafts can be used for the spying operation using various recon missions. Hypersonic based research is carded out by many other nations like the India (DRDO), Australia, Germany, UK, Japan and France on their various platforms like in Missile Development and UAV (Unmanned Ariel Vehicles).There are other various experiments focused on the testing of the Scramjet powered vehicles like HyShot II experiment in 2002 by the University of Queensland Australia Centre for Hypersonic to demonstrate the supersonic combustion during the Ram flow which happened in Scramjet platform of systems by the help of sounding
Rockets. One of the experimental vehicles of US (NASA) named X43 was scramjet powered vehicle led Hyper X program, another one that is X 51 Waverider unmanned vehicle built by the USAF which was launched in air by the flying B 52 bomber aircraft.

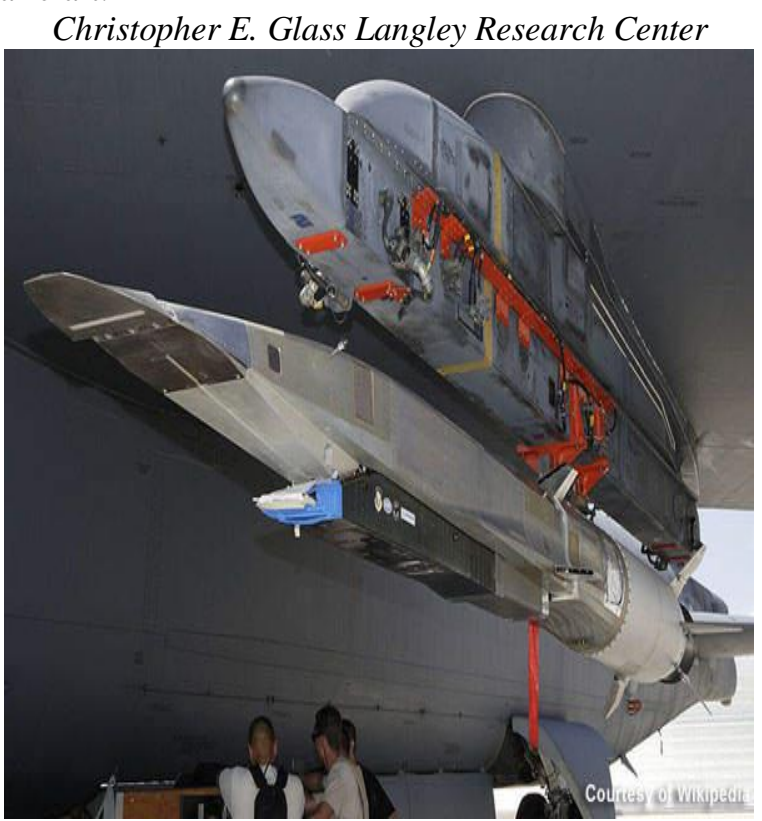

\section{[ X 51 Waverider ]}

\section{CONCLUSION}

Finally, our focus is to design and develop a safe and secure technology that can be accepted by the community with trust and believe. The design of a typical hypersonic vehicle can be under taken by a successful experimental test in a ground-based facility and Ariel testing. Hypersonic flight is the futuristic_concept not only limited to Earth based travels but it has a vast scope for the deep space and interplanetary exploration through hypersonic space craft's because that concept is successfully driven with Rocket propulsion system also_who will take the humanity on the next level.

\section{REFERENCES}

[1.] Airframe Research and Technology for Hypersonic Airbreathing Vehicles David E. Glass, N. Ronald Merski, and Hampton, Virginia," NASA/TM-2002-211752.

[2] Vehicle Flight Dynamics with Coupled Aerodynamics and Reduced-order Propulsive Models Derek J. Dalle_, Scott G. V. Frendreisy, James F. Driscollz, Carlos E. S. Cesnikx University of Michigan, Ann 


\section{International Journal of Engineering Applied Sciences and Technology, 2019 Vol. 4, Issue 7, ISSN No. 2455-2143, Pages 158-164 \\ Published Online November 2019 in IJEAST (http://www.ijeast.com)}

Arbor, MI 48109 AIAA Atmospheric Flight Mechanics Conference 2 - 5 August 2010, Toronto, Ontario Canada

[3.] Torrez, S. M., Driscoll, J. F., Dalle, D. J., and Fotia, M. L., "Preliminary Design Methodology for Hypersonic Engine Flowpaths," 16th AIAA/DLR/DGLR International Space Planes and Hypersonic Systems and Technologies Conference, 2009.

[4.] Mirmirani, M., Wu, C., Clark, A., Choi, S., and Colgren, R., "Modeling for Control of a Generic Airbreathing Hypersonic Vehicle," roceedings of the 2005 Guidance, Navigation and Control Conference, AIAA Paper No. 20056256, August 2005.

[5] Chavez, F. R. and Schmidt, D. K., "Analytical Aeropropulsive/Aeroelastic Hypersonic-Vehicle Model with Dynamic Analysis," Journal of Guidance, Control, and Dynamics, Vol. 17, No. 1994, pp. 1308-1319

[6.] HYPERSONIC VEHICLE CONSTRUCTION , ANALYSIS USING 2D FLOW FIELDS

Haile Lindsay and Frederick Ferguson, Stephen Akwaboa North Carolina A\&T State University, Greensboro, North Carolina, 27411 And Hydar Apdin Michelin North America,Greenville, South Carolina, 29615

[7.] Young, A.D., "Modern Developments in Fluid Dynamics', Vol. 1, High Speed Flow, Oxford University Press, 1953

[8.] Apdin, Hydar, Ferguson, Frederick, and Zhang, Shenygong. An Engineering Method for the Construction and Analysis of Hypersonic Vehicle Configurations., 13th AIAA/CIRA International Space Planes and Hypersonic Systems and Technologies, Italy, May 16th 20th,2005, AIAA Paper 2005 - 3364.

[9.] Hypersonic Aerodynamics Space Shuttle in NASA Langley Helium Tunnel at $\mathrm{M}=20$ (NASA SP-440)

[10,] Aerodynamic Design Analysis of the HEXAFLY-INT Hypersonic Glider Giuseppe Pezzella1, Marco Marini2 CIRA, Italian Aerospace Research Center, Via Maiorise, 81043 Capua (CE), Italy Bodo Reimann3, German Aerospace Center (DLR), Lilienthalplatz 7, 38108 Braunschweig, Germany and Johan Steelant4 ESA-ESTEC, European Space Agency, Keplerlaan 1, 2200 AZ Noordwijk, The Netherlands

[11.]Apdin, Hydar. An Engineering Method for the Design and Analysis of Waverider Derived Hypersonic Vehicles., M.S. Thesis, North Carolina A\&T State University, 2004
[12.] Scott, Jeff, Hypersonic Waveriders., 2000.

[13.] Kevin G. Bowcutt, "Multidisciplinary Optimization of Airbreathing Hypersonic Vehicles,"Journal of Propulsion and Power, Vol. 17, No. 6, Nov-Dec 2001, pp 1184-1190.

[14.] John D.Anderson "Fundamentals of Aerodynamics" Third Edition, 2001, McGRAWHILL

[15]. Kuchemann, D. “The Aerodynamic Design of Aircraft", Pergamon Press, New York, 1978.

[16.]https://www.google.com/imgres?imgurl=http $\% 3$ $\mathrm{A} \% 2 \mathrm{~F} \% 2 \mathrm{Fwww}$.aerospaceweb.org 